\title{
Methodology of Internal Corporate Distribution of External Orders
}

\author{
Oleg Dmitriev $^{1} \&$ Sergey Novikov ${ }^{1}$ \\ ${ }^{1}$ Moscow Aviation Institute (National Research University), Moscow, Russian Federation \\ Correspondence: Oleg Dmitriev, Moscow Aviation Institute (National Research University), Moscow, 4, \\ Volokolamskoe Highway, 125993, Russian Federation. Tel: 7-963-753-7110. E-mail: olegdmitriev@yandex.ru, \\ danonik92@mail.ru
}

Received: April 28, 2020

Accepted: July 19, 2020

Online Published: September 14, 2020

doi:10.5430/rwe.v11n5p433

URL: https://doi.org/10.5430/rwe.v11n5p433

\begin{abstract}
A hierarchical subject complexity of the market for marketable products in modern times is revealed. The emergence of cognitive dissonance concerning supplier subjectivity of marketable products with an unincorporated customer is reflected. The main emphasis is made on the presentation of the conceptual mechanism vision of internal distribution of the external order, i.e. the supply project decomposition for the enterprises (the corporation members). The mechanism is considered in the aspects of environmental, structural and procedural scientific and project execution.
\end{abstract}

Keywords: corporation, distribution, enterprise, optimization, order

\section{Introduction}

The large-scale corporatization of high-tech enterprises is typical for modern Russian conditions including the aviation industry (Bodrunov et al, 2000; Bodrunov, Dmitriev \& Koval'kov, 2002; Dmitriev et al; 2013; Demchenko, 2011; Milovanov, 2014). This process began at least a century ago in the world and 25 years in modern Russia.

One of the most serious problems is still that institutional innovation lags critically behind managerial innovation (Dmitriev, 2017). They turned out rather to be spaced out and even isolated from each other spheres. The corporate groups (corporations) have been created as extra-legal organizations, but these institutional separations were not scientifically designed. The methodology basis of creation concerning corporations was primitive: these separations were built on more than discussion methodological principle such as "as is". All of them are information and reference regardless of this (Dmitriev, 2005) and therefore do not allow reaching the minimum intelligence level of their development. The basic used scheme is the scheme of intuitive empirical management (Dmitriev, 2005).

The effectiveness of their functioning cannot be assessed as acceptable, and the prospects for evolutionary improvement in the situation are more than pessimistic. This situation is seen as reinforced by deterioration forecasts of the sanction's situation.

Naturally, that the main or final sources of financing for corporations and its member enterprises directly are proceeds from the sale of marketable products manufactured by member enterprises of the corporation. Then these enterprises inevitably participate in supply projects, i.e. in the production of marketable products (directly or securely).

The authorized Government bodies of Russia are among such customers for Russian high-tech enterprises and corporations, as well as foreign customers in the framework of military-technical cooperation, for example.

Such orders may take the form of a state order, including those related to the implementation of federal target programs and similar management tools, municipal order, etc.

It is subject to distribution among the member enterprises of the corporation and non-corporate enterprises possibly, if such order arises (we will discuss some legal nuances below). However, we confine ourselves only to the consideration of intra-corporate distribution of the external orders.

\section{Applicability of Practical Experiences and Theoretical Researches of the Forerunners}

The experience of internal distribution of external (in relation to enterprises - members of the corporate grouping) orders is very long and extensive. Of course, there is no rational meaning of the analysis of the problem in relation to too distant eras. Therefore, we are going to consider only the next stage of the functioning of the economy. Of course, 
in this sense, when conducting a retroanalytical review, a corporate grouping should be interpreted broadly: as a meso scale grouping of enterprises, regardless of the organizational-economic scheme of corporatization applied (Dmitriev, 2013).

In the framework of international production cooperation, quite often the choice was made between enterprises similar in terms of production and technology located in different countries (Zuev, 2014) and in various regions (Rodionov, 2004), including differing tax systems (Dmitriev \& Novikov, 2018b). Moreover, the selection criteria were the following:

- level of fiscality - both in terms of "traditional taxes" and in terms of export-import duties. A special case was the case of the so-called tolling scheme (we can see, for example, in relation to the production of aluminum products in Russia in the recent past (Cherner, 2004)). A separate case is the investment creation of alternative production and reserve capacities in relation to their expected load of orders (Bokarev, 2006);

- level of country localization of production in terms of the so-called import substitution (Kirbitova, 2019);

- level of employment for the local population (Petukhova, 2016), etc.

We need to note that these optimization criteria were limitedly representative and / or were of a non-cost nature. In addition, their evaluation was questionable.

A very characteristic and generally well-known historical example was associated with the intersectoral distribution of orders for rocket carriers, implemented in the USA and the USSR after the Second World War. In the United States, the corresponding orders were placed in the aviation industry complex (now the aerospace complex), and in the USSR in part, including at artillery weapons production capacities and at some enterprises of the aviation industry, which were later transformed in a group order together into a separate national missile and space industry. That is, the task was set and solved of interbranch distribution of orders for a fundamentally new type of marketable products.

Many high-tech industries of the USSR were characterized by the alternative of placing orders, including the so-called export ones. Such examples were typical, for example, for the aviation industry. In this case, the corporate grouping was an industry or a sub-industry (for example, aircraft engine sub-industry). Distribution of orders was carried out by a hybrid bureaucratic-analytical method. Actual data on the state of enterprises was collected and their capabilities were comparatively assessed in terms of the components of the production and technological potential for the implementation of the relevant order. At the same time, managers tried to maximize the utilization (loading) of production capacity. Preference in terms of placing some order was given to the enterprise that was most prepared in the production plan for the execution of the order. A characteristic feature was that the whole range of specialized products to be produced was considered: all orders were distributed among all enterprises in the industry. At the same time, various subjective factors had a very significant impact, including informal views and the influence of regional administrations, directorate of enterprises, employees of the apparatus of the USSR Ministry of Aviation Industry and personal commitments of employees of the higher Communist party and Government apparatus. In the context of conversion and transition to a market economy (Bratukhin, Dmitriev \& Koval'kov, 1992), unhealthy competitive conflicts began to arise between manufacturing enterprises, which were informally settled at the industry level.

In the current conditions of the holding corporatization, the problems of the distribution of "external orders" have been concentrated in certain management inter-holding structures, the legitimacy of which is quite debatable in the modern Russian legal space. A rather similar situation is in the so-called Russian State Corporations. As a result, relevant decisions are most likely formed on the basis of an intuitively empirical approach or the formation of simplified business plans. The situation is significantly complicated by the fact that the placement of, for example, state orders is made on a competitive basis in accordance with the valid until 2014 Federal Law "On the Placement of Orders for the Supply of Goods, Performance of Work, and the Provision of Services for State and Municipal Needs" of July 21, 2005, № 94-FZ. It is also appropriate to mention the Federal Law "On procurement of goods, works, services by certain types of legal entities" of July 18, 2011, № 223-FZ. According to it, the producer/supplier of marketable products should participate in the competition, which contradicts the conceptual idea of the corporation, in which the corporate grouping is the pseudo-legal relation for its pseudo-counterparties. As a result, either the company managing the corporate grouping must participate in the tender, and then distributing the won order internally, or the company is a member of the corporate group ignoring the company managing the grouping. In the case of an auction nature of the placement of an order, the subjectivity problem "enterprise - member of a corporate grouping $\leftarrow \rightarrow$ corporate grouping" becomes an unsolvable legal conflict.

A fairly separate practical area is the formation of Russian Federal Target Programs, where, within the framework of 
the program activities section, some subjects are indicated, the choice of which is largely the product of informal agreements (Dmitriev \& Novikov, 2017b; Dmitriev \& Novikov, 2018a).

In general, two problems should be noted that are now characteristic of the realities of the existing sphere of internal distribution of external orders between enterprises - members of the corporate group:

- focus on the primitives and archaic of the intuitive empirical conceptual scheme for the formation of distribution and redistributive managerial decisions (Dmitriev, 2005; Dmitriev, 2017);

- contradiction between the managerial statuses of two types of organizational and institutional breakdowns: enterprises and corporate groupings of enterprises (usually holding ones) (Dmitriev et al, 2013, Dmitriev \& Novikov, 2017a).

These problems are characteristic of Russia and, most likely, of other market-based non-primitive economies.

With regard to theoretical research, the situation is as follows.

According with the Russian State Library content, neither dissertations were defended nor books were published on these issues in the USSR and Russia (actual access to the website www.rsl.ru, on July 14, 2020).

The situation in the foreign world information space looks somewhat different.

It seems appropriate to distinguish several classification types of research, namely:

- studies in relation to the identification of cooperative supply chains of homogeneous marketable products (Fellhauer \& Strożek, 2010). In this case, the formation of chains for an already specified ordering specialization of enterprises is considered;

- studies related to the aggregation of the distribution of orders and corporate satisfaction as a means of corporate discrimination (Comegys, 1967);

- studies related to the analysis of incoming orders in network structures and their distributions by distribution points. Similarly, in the part of Internet networks engaged in trade and delivery of goods to the population.

A remote and conditional analogy of developments in the field of internal distribution of orders can be conditionally recognized as studies to optimize group defense against a group of homogeneous or heterogeneous objects that produce an attack. Within the framework of these traditional studies, goals are recognized as antivalued and are subject to destruction or damage: maximum or rational. If we change the interpretation of the conflict situation to non-conflict one, we can recognize that the means of "attack" from antiqualities are transformed into values for the defending side. Such scenarios are played out in some special sections of biology, when active / aggressive biological objects turn into the feed base of the objects they attack. In this case, the "attackers" are distributed so that the results are as best as possible for the "defending" side, and the means of attack become sources of profit. However, traditional developments in this area still dominate the case of traditional interpretations of conflicts (Bodrunov, Dmitriev \& Koval'kov, 2002; Shubin, 2005).

In general, it was not possible to identify a distinguishable set of specialized publications on positioned issues, including the Library of Congress of USA (current access to the website www.loc.gov, July 14, 2020).

Accordingly, there are good reasons to state that the issues considered in the article have no tangible background either in relation to Russia or in relation to other countries.

It seems to be a direction within the framework of corporate conflict resolution.

\section{Methodology}

The principal feature of the applied research methodology. A significant part of modern research has the character of testing or using a priori available methods and technologies, calculations, estimates, and generalizations of empirical material. A typical example is research in the field of sociology, in which primary data is collected on the basis of known tools, and then processed, and the study is completed by interpreting the results. Unfortunately, today many specialists still identify scientific research primarily with the preparation of initial data, in fact, with the utilitarian application of methodologies and methods already created by the forerunners. However, along with this kind of purely applied research, scientific developments are carried out that are focused on the formation of the methodological foundations, methods and tools for conducting so-called "field research". With all the applied utility of processing research, the intellectual base of science is made up of methodologies and methods. Experimental research is often the domain of technical performers, and methodological research is the prerogative of high-level scientists. 
In the first case, the presentation of the results of the study resembles the classical description of the experiment in structure: what you wanted to get, what tools were used (your own or attracted ones, it does not matter), what experiments were executed, what was obtained, and how it should be understood. This is a kind of positive classical categorization of the forensic expert's opinion.

In the second case, the presentation describes the outline of the synthesis of the methodological or instrumental apparatus. Thus, the methodology of methodology synthesis is to be distinguished in some way. In this situation, only a set of scientific theories, directions, and universal methods can act as an external scientific set-up. The construction "detailed method for obtaining a detailed method" seems illogical.

Used methodological tools. The results of the study presented below are typical for research aimed at developing the methodological basis. There is a right to exist the statement that the development of one of the special methods of performing operations research is considered below.

Accordingly, the methodological basis of the study was as follows:

- system analysis;

- general control (management) theory;

- jurisprudence;

- organization theory;

- institutional theory;

- evolutionary theory;

- optimization theory;

- set theory;

- theory of active systems;

- information theory, etc.

\section{Results and Discussion}

Problem area. We consider a situation where the head supplier of marketable products formed or used some corporation of a fixed subject composition. It may be used, for example, according to the subsidiary participation scheme, to the holding scheme or by some kinds of pseudo-corporation organization.

Accordingly, it should solve the problem of distributing one order or some orders set received by the lead supplier from the external customer: from outside the corporation. We will consider that not a single corporation member is the customer of the commodity products of the parent supplier. In other case, the infinite recursiveness can occur, and this event is extremely unlikely in practice. But sometimes it is necessary take into account the situation when the object of delivery is internal corporate information.

Accordingly, the parent supplier has the status of a structure-name and structure-management enterprise.

Obviously, the order can be presented in the form of the sub-orders system, each of which is an order to be distributed in one's turn.

Therefore, a one order or group orders of the lead supplier can be represented as a orders group.

Applicability affected. One of the directions of anti-crisis development in our economy is corporatization. However, it is only an organizational and economic mechanism that creates some important prerequisites for establishing effective internal corporate governance, which is implemented in the case of a multilateral and fundamental update of the management sphere.

A significant problem in the formation of contractual chains is that the marketable products supplier must have production potential, and not manufacturing enterprises dependent on it, in accordance with current Russian legislation, for example, under a state defense order. Therefore, there are so far unresolved legislative problems that are ignored in the framework of the actual operation, which is seen as fraught with serious damage.

The world experience of a market economy irrefutably indicates the mandatory transition to a corporate subject structure, primarily in the interest of creating the prerequisites for ensuring the functioning of the market mechanism for the consolidated resources redistribution and the managerial activity harmonization of all management entities. However, the corporatization abroad proceeded and continues to be implemented in a fundamentally different legal, economic, technological and social space. As a consequence, the borrowing of foreign experience cannot but have a 
critical, and thereby selective and transformational character.

Therefore, it is legitimate to state that now there is an objective need to solve a fundamentally new task of internal corporate governance, including optimizing the distribution of orders between enterprises included in the corporation.

It follows from the above considerations that domestic research in the field of corporate governance due to natural, objective reasons (even only due to time limitations) could not get any noticeable development. However, a number of studies are known at the same time, on the one hand, carried out in closely adjacent areas, and on the other hand, allowing productive use in the interests of the internal distribution of orders, a mention should be made, for example (Cherner, 2004; Pilyugina, 2008; Dubovik, 2009).

The foreign scientific background and experience in corporate governance are undoubtedly much richer. However, this is no closer to solving the problem.

Firstly, the basic intellectual values are concepts and tools supporting the adoption of managerial decisions for specific corporations do not become public domain. Not-public information presented in fragmentary descriptions, emphasis is placed on the external outline of management mechanisms, and their methodological and hardware content are not disclosed. This is due to several reasons: from the implementation of measures to prevent antitrust and tax prosecution to the desire to manipulate the transparency of the financial and economic condition of their corporation.

Secondly, there is another factor operating in the same direction, such as the widespread practice of implementing management precedents abroad. According precedents corporate managers are carriers of corporate governance technologies and implement them at their place of work through organizational design of subordinate administrative and managerial staff.

Finally, thirdly, the internal corporate governance abroad thirdly is organized and carried out in an environment that is quite foreign to Russia as already noted above.

The lack of specialized translated publications in Russian (even popularizing ones) is also a sure sign that so far, the corresponding developments do not cause wide interest among domestic developers and managers.

Thus, it can be summarized that in the available publications not only an exhaustive solution of the problematic management task under consideration is presented, but it is not even holistically considered in the post-production perspective.

Therefore, the conclusion about the relevance of this study is valid.

The agreement idea and coordination of internal marketing operations. Enterprises can use the following two methods of intra-corporate coordination of marketing operations under the modern conditions, considering the restrictions imposed by Russian law:

- introducing, amending and voluntarily extending to itself a framework mechanism for substantiating the contracts terms governing their contractual relations (however, one of the cases of implementing this method is the refusal of corporate regulation);

- undertaking the justification of these terms of enterprise contracts, that is, the corporation members enterprises within the established framework mechanism.

These features determine the fundamental difference between the contractual relations management of enterprises within the corporation and outside this framework, because the contractual relationships management outside the corporation is fundamentally simplified and comes down to direct optimization of the entire spectrum contracts terms. I.e., the moments related to the framework mechanism fall out altogether, and when optimizing the contracts terms, the corresponding corporate restrictions fall out as a category.

It is important to emphasize that the listed methods for managing the contractual relations of enterprises: the corporation members are implemented by all these enterprises, i.e.:

- framework mechanism for substantiating the contracts terms is adopted by all enterprises based on the consensus rule in the context of the general group specialized agreement. Proposal packages for its revision are formed in two ways. Firstly, the structural management company generates these proposals on a mandatory basis regularly (independently or with the involvement of third-party organizations). These proposals may be specific reforms with an assessment of the expected consequences of their application and may also take the conclusion form on the advisability of maintaining the current framework mechanism 
unchanged. These proposals are formed in the event of a significant change in the managerial situation as soon as possible and are submitted for discussion and adoption by all enterprises. Secondly, each of the enterprises has the right to make proposals to change the framework mechanism on an initiative basis and at arbitrary points in time;

- justification of specific contracts the terms is carried out by all enterprises (the corporation members) that are parties to the relevant contracts. In this case, either the presumption rule of conformity can be implemented (the contracts are considered consistent with the current framework until one of the enterprises, the corporation members proclaim otherwise, or the certification rule (all contracts are recognized as transparent to the corporate supervisor and are transferred for independent examination to corporate arbitration court). There may be varieties, for example, only "substantial" contracts that comply with the framework mechanism of the materiality condition.

In principle, the above two methods can be supplemented with procedures for changing the framework mechanisms, i.e. rules for changing rules, for which you must enter your own rules for changing rules in one's turn, etc. Accordingly, an endless loop of nested rules for changing rules arises theoretically. The task of forming such infinite nested procedures has not been worked out theoretically now, including the admissibility limits of replacing an infinite loop with a finite length of the latter. Therefore, the task of forming a system of nested rule changes has not been studied in this study.

Regulation of communications. A semantic regulation of the nature of these relations is necessary to implement the two management methods of the contractual enterprises' relations between the corporation members chosen above through the frame-work mechanism for substantiating and justifying the contracts terms.

The idea of emulating a special managerial environment. The only way to accomplish this is to emulate a special intra-corporate business environment, regulated by a general, special or a group of special general agreements of all enterprises: the corporation members, including a structural management company. An important feature of the corporate general agreement is its fundamentally consensus nature, i.e. it can be adopted only with the all enterprises consent, each of which receives a veto.

This environment provides the following:

- delegation of a significant part of the contractual enterprises' relations between the corporation members with other enterprises and persons with special status (federal and regional authorities) to the structural management company, which will be most prominent when introducing a consolidated balance sheet. These relations are determined by the "passing" through the structural management company of orders (including state and export orders), logistics, syndicated insurance and lending, taxes, etc.;

- introduction of exclusive internal corporate contractual relations related to the internal corporate financial and economic resources management;

- special nature introduction of establishing and filling in contractual relations between enterprises: the corporation members, based on corporate interests.

The proposed conceptual principles for the formation and the mechanism functioning of intra-corporate entrepreneurship lay a powerful potential for the development of this organizational and economic mechanism.

This emulated mechanism allows development in the direction of corporate guarantees, bill circulation, etc.

Intra-corporate coordination of marketing operations in this environment includes the entire traditional arsenal of market economic management.

The framework mechanism determines in this case the boundary conditions of the agreements that affect the following relationship:

- "ordinary" enterprises: the corporation members among themselves;

- "ordinary" enterprises: the corporation members with a structural management company;

- "ordinary" enterprises: the corporation members with other enterprises, i.e. not part of the corporation;

- structural management company with other enterprises.

Requirements for specialized management. The corporation is presented with a system of self-governance system requirements arising from the following:

- boundaries of the permissible state of the managed object during the functioning and development of the 
managing system;

- maximum permissible characteristics of the processes of creation, deployment, functioning and development of the managing system, i.e. the boundaries of their permissible course.

Accordingly, the assessments of the maximum permissible financial and economic performance and the financial and economic condition of the corporation come forward as prohibitive assessments that specify requirements for the corporation's self-Government system.

We will proceed from the following prohibitions.

The following should be provided for each of the enterprises: the corporation members:

- inconsistency elimination of their financial and economic condition with the current Russian legislation (only for the situations within scope of Russia, in other countries natural national legislation should be taken in account), including violations of legislative regulations, regarding the minimum allowable authorized capital, mandatory in-crease of the net assets value over the authorized capital amount;

- avoidance of financial insolvency (bankruptcy);

- inadmissibility of unacceptably low profitability.

These prohibitions may be supplemented by prohibitions for the corporation. For example, a banning on consolidated financial insolvency may be introduced.

The following requirements are assigned to the distribution self-management system by the corporation in terms of collateral based on the above-mentioned prohibitions:

- non-contradiction of activities in relation to for all stages of its life cycle regarding the Russian legislative space and the legislative spaces of another subjects of foreign law. These subjects are detected as territories on which the conditional production and economic activities of the corporation will also be carried out through its member enterprises;

- ratio error of managerial decisions at a level of not more than $10-15 \%$;

- reactivity level (response period) of the managing system at the units level of minutes for the operational circuit and units hours for the strategic management circuit;

- first stage operability no later than 1-2 years after the start of its development;

- certain comfort level for the management personnel work, implying the claims barring of the exclusive knowledge in the field of computer science and computer technology, the refusal to generate stress-generating queries in the face of de-liberate uncertainty, as well as minimizing the harmful effects on the body and creating conditions for increased ergonomics of management activities;

- innovation payback no later than 2-3 years from the project start to create a specialized self-management system for the corporate structure;

- maximum annual level of innovation costs (without the cost of management personnel and platform upgrades) in the first place, the corporation's self- management system should not exceed a certain level, for example, $1 \%$ of the total enterprises costs;

- information retention requirements constituting state, military, commercial and banking and other secrets.

The organization of distribution self-management corporation should provide for two following parallel categories of management processes:

- organizational design of a managing system for a corporation in relation to its creation and development;

- organizational use of this designed managing system in its operation.

The conceptual scheme of the feasibility study of managerial decisions extends to both of these management processes categories. I.e. all the basic management functions should be implemented, among which the indispensable ones (Bodrunov, Dmitriev \& Koval'kov, 2002; Dmitriev, 2005; Dmitriev et al., 2013) are the current state the assessment and the managerial decisions optimization.

The composition of the design components of the mechanism. The methodologically complete design for all types of self-management includes the following components that are correlated with the design of a specialized management mechanism: 
- general environmental design, i.e. the principles' design (from the word "principle") of nature of the intraorganizational management environment;

- structural design, providing for the hierarchical topology of intraorganizational structure. This design include the determination of the hierarchical set of enterprises, services, structural units and individual jobs, as well as functional areas the assignment of their managerial competence in terms of managerial rights and mandatory constraints. Documentary areas of managerial competence must be fixed in the provisions about structural units and in personnel job descriptions, for example;

- procedural design, which implies the procedures formation for the interaction of the enterprises (corporations members). It should apply for the enterprises, for time periods, for supply projects, etc.;

- HR-design related to the release of administrative staff on jobs. The personnel organizational design is quite distinct and implemented as a rule after the general environment completion, structural and procedural organizational design.

There is also highlight organizational redesign within the design framework, i.e. the case of introducing structural and competency-based innovations into an existing managing system of an organization.

We restrict ourselves to further consideration mainly of design issues in relation to the intra-corporate management under consideration.

The conceptual solution within the framework of the general environmental design. The above considerations regarding problems, conceptual mechanisms, and prospects for the corporation's self-management system lead to an unambiguous conclusion concerning the advisability and realizability of introducing the universal approach in relation to the formation and use of the organizational and economic management environment.

This approach is as follows:

- in the introduction of the mechanism providing for the interpretation of counterparty relationships between active and passive management sub-objects in the form of an emulated organizational and economic environment for their joint functioning and development. This environment must to be a natural or artificially created entrepreneurial character. The fixing of this mechanism is carried out either on the basis of the voluntary consent of the corporation members that administers in relation to these sub-objects, or appointed for them by force and from the outside, i.e. by a person endowed with authority in relation to these members;

- in the organization and implementation of management concerning managed object, ordered using the specified mechanism, based on the use of intelligent management technologies for the formation of managerial decisions for the internal orders distribution (recommended DSS). We note that the distribution should be carried out for a group of external orders, and not for a separately allocated order, in order to avoid the problems of causing decomposition errors. In this sense, the practice of prolonged annual management orders is a factor that greatly complicates the management environment.

Thus, it turns out the primary and secondary management in some way. Both managements are multi-point. In fact, both the emulated organizational and economic environment of functioning and development, and managerial decisions within it can change, as appropriate.

Accordingly, two levels or two categories of managerial decisions arise: firstly, streamlining the internal corporate environment, disciplining and interpreting it, and secondly, providing for the implementation of measures and activities within its framework.

The conceptual solution in the framework of structural and procedural design. The principal feature of this managed object is that its sub-objects (the enterprises as the members of the corporation) are active systems, i.e. they have their own and inconsistent or conflicting goals of functioning and development, they have inalienable rights to achieve their priority and use these rights in the process of carrying out their production and economic activities.

Therefore, the two following fundamental management problems in the organization of internal corporate governance are to be resolved:

- formation and use of tools for substantiating managerial decisions for each of the management subjects: they are each of the "ordinary" enterprises: members of the corporation and the structural management company as the organizational center of the corporation;

- formation and use of tools for the harmonization of these managerial decisions. 
It is well known from the management theory that the tasks of the so-called arbitration optimization are not only unsolvable in the general case (Dmitriev, 2011), but they cannot be correctly formalized even so far. This is due to the emergence of the multiple recursive problem. Moreover, if the progress in solving the general problem of two-point recursiveness is observed quite clearly, then the problems of multi-point recursiveness have not yet succumbed to an effective study.

Accordingly, the conceptual approach is still the only practically applicable, focusing on the choice of a single managing subject and taking into account the remaining operating parties in the form of a restrictions system for a certain group of state indexes. These state indexes characterize the usefulness orientation of managing subjects who are practically denied the right to react actively. Thus, these subjects are forcibly transformed into passive management sub-objects that are not endowed with their own managing systems. In this case, the problematic management areas automatically merge into a single area, because the problem of coordinating managerial decisions of various management entities is brought to checking the violation or non-violation of the restrictions system. Therefore the multi-point re-cursive task thus turns into a problem of conditional non-recursive optimization of managerial decisions for a single managing subject.

A semantic regulation of the nature of these economic relations is necessary to implement the two management methods concerning the enterprises: members of the corporation relations selected above: through the framework mechanism for justifying the contracts terms and justifying the contracts terms.

The only way to accomplish this is to emulate a special intra-corporate business environment, regulated by the general agreement of all enterprises: the members of the corporation, including a structural management company. An important feature of such a corporate master agreement is its fundamentally consensus nature, i.e. it can be adopted only with the consent of all enterprises, each of which receives a veto.

The structure of such an emulated internal corporate business environment is presented (Dmitriev \& Dergunov, 2003; Dmitriev \& Dergunov, 2004; Kanashchenkov et al., 2005; Dmitriev et al., 2011) in the Figure 1. Here, "CS" stands for "Corporate Structure" (it is also an integrated structure, corporate grouping).

This environment provides the following:

- delegation of a significant part of the economic enterprises (corporation members) relations with other enterprises and persons with special status (federal and regional governing bodies) to a structural management company. It will be most prominently manifested when a consolidated balance sheet is introduced. These relations are determined by the "passing" through the structure-management enterprise of orders, logistics, syndicated insurance and credit, taxes, etc.;

- introduction of exclusive intra-corporate economic relations related to intra-corporate management of financial and economic resources;

- introduction of the special nature of the establishment and filling of economic relations between enterprises: the corporation members based on corporate interests.

The proposed conceptual representation of the formation and functioning of the intra-enterprise entrepreneurship mechanism lays a powerful potential for the development of the organizational and economic mechanism under consideration.

The economic relations management by this enterprise: the member of the corporation type is obviously identical in composition of managerial decisions to corporate governance/management in terms of establishing the nomenclature and parametric filling of managerial decisions of contractual terms (framework and implemented) and fundamentally differs by criteria and restrictions. Therefore, the optimal framework mechanism for the corporation and each enterprise, is their own in principle and it is advisable to seek such a framework mechanism that would ensure the best financial and economic results for the corporation, while the financial and economic results of individual enterprises are acceptable, and then the terms of all agreements concluded subject to optimization within the framework of this mechanism.

We note that the above constructions apply to almost all Russian corporations (even covering the area of hierarchical holdings), because the above corporation interpretation is universal (Dmitriev \& Novikov, 2017).

The system-technical implementation of the mechanism is published by other authors (Kanashchenkov et al., 2005; Dmitriev et al., 2011; Dmitriev, 2019).

The completed development was applied in practice as follows: 
- when substantiating projects for the organizational transformation of several Soviet and Russian high-tech enterprises after the mid-1980s until the present time;

- in the formation of the institutional and organizational-economic appearance of several emerging high-tech Russian holdings in 1996-2006 (mainly in the aviation industry);

- while optimizing the distribution of a number of critical long-term orders for complex technical products (products of a number of high-tech industries) after the mid-1980s until the present time.

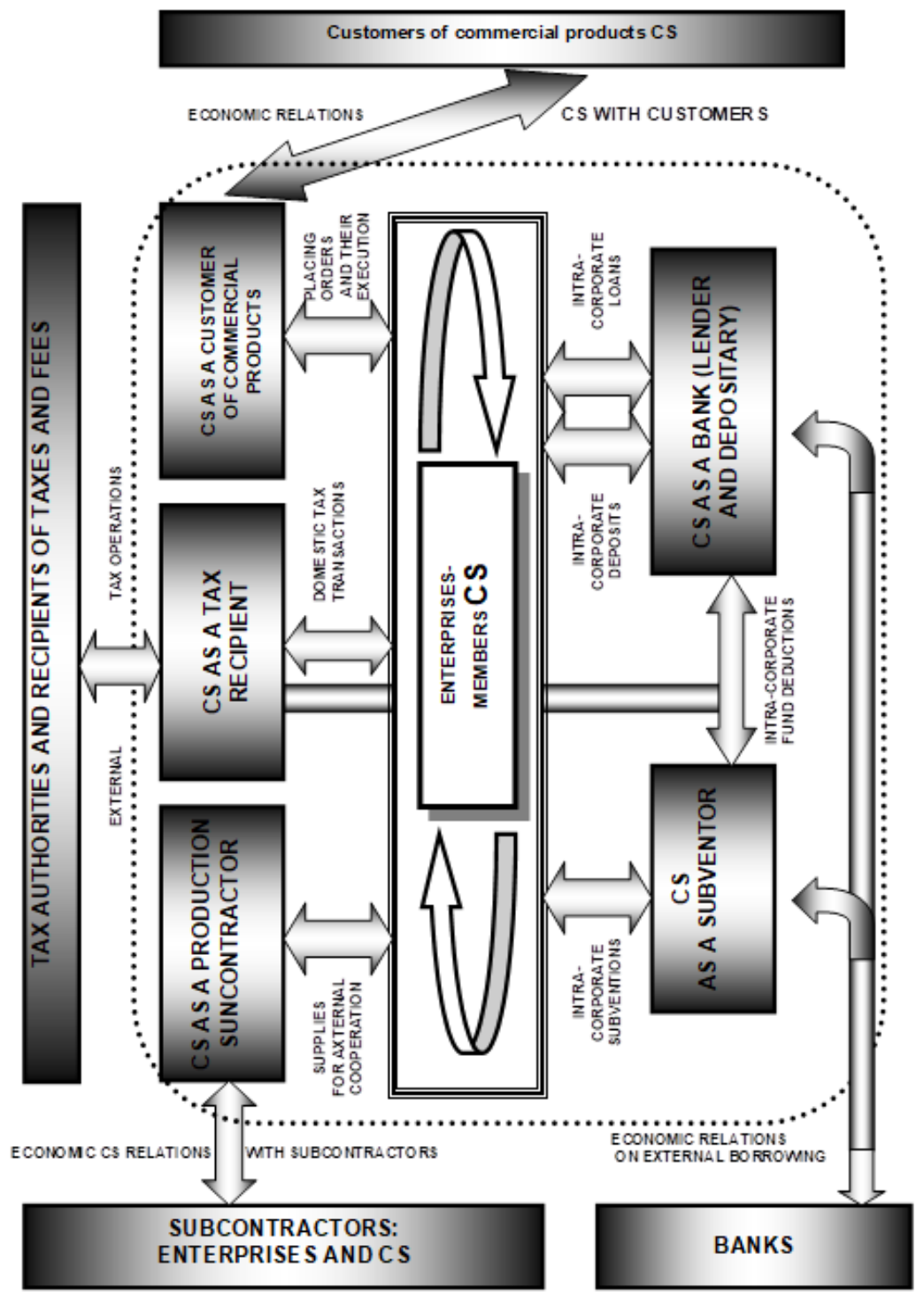

Figure 1. The structure of the emulated organizational and economic environment of intracorporate regulated entrepreneurship

Source: authors' own researches

\section{Conclusions}

We have the following from the above:

1. Corporations in the world, including in Russia, are indispensable institutional localizations. 
2. The corporation's formation has changed the subjective structure of the market, adding pseudo-entities in the corporations' form that are not individuals in several countries, including Russia. Thus, the market began to represent at least a two-level hierarchical structure.

3. The diversity practice of the internal corporate governance/management and external orders placement (primarily state orders) used in Russia gives rise to an insoluble managerial conflict, as well as legal conflicts.

4. Well-known theoretical studies almost do not affect the problems of internal distribution of external orders.

5. There is a distribution problem of the order among enterprises - the corporation members regardless of the problem participation resolution of structure-controlling enterprises in placing the order.

6. The emulation of the internal corporate market is required, which is additionally regulated by the internal corporate mechanism for the distribution of orders to solve this problem.

7. This distribution should provide for the implementation of a system-wide procedure for the internal distribution of external orders among enterprises: the corporation members.

8. The substantiation of decisions on the internal distribution and redistribution of corporate orders should be carried out using an intelligent DSS environment that supports deep feasibility studies and is based on a mathematical model of corporate grouping.

9. The testing of the development showed its applicability and high efficiency in a number of critical management areas.

\section{References}

Bodrunov, S. D., Dmitriev, O. N., \& Koval'kov, Ju. A. (2002). Aviation-industrial complex of Russia on eve of the 21st century: problems of effective management. / Monograph. St. Petersburg: Aerospace Equipment Corporation.

Bodrunov, S. D., Dmitriev, O. N., Koval'kov, Ju. A., Manturov, D. V., \& Fedorova, O. N. (2000). Problems, principles and methods of corporatization of aviation-industrial complex of Russia / Monograph. St. Petersburg: Aerospace Equipment Corporation and Publisher House "Petrovsky and Co".

Bokarev, P. A. (2006). Technology of intra-corporate investment management in the sphere of modern Russian science-intensive industry: Dissertation for the competition degrees of candidate of economic sciences (PhD). Moscow: Moscow Aviation Institute.

Bratukhin, A. G., Dmitriev, O. N., \& Koval'kov Ju. A. (1992). Potencial of convercion. Monograph. Moscow: Mashinery Building.

Cherner, N. V. (2004). Intra-corporate price management in conditions of multi-share production. Monograph. Moscow: Gnome and D.

Comegys, W. B., Graham, R. W., Jones, M. G., Kaapcke, W. L., von Kalinowski, J., \& Williams, L. L. (1967). Panel Discussion - "United States V. General Tire and Rubber Company: Intracorporate Conspiracy and Sherman Act Reciprocity". Antitrust Law Journal, 36, 102-141.

Demchenko, O. F. (2011). Mathematical modelling methodology of organizational structures of the Russian Federation aviation industry. Monograph. Moscow: KnoRus.

Dmitriev, O. N. (2005). System analysis in management. Moscow: Good Word.

Dmitriev, O. N. (2011). Conceptual problems of substantiation of arbitration administrative decisions in economy. Proceedings of Moscow Aviation Institute, 49.

Dmitriev, O. N. (2017). Strategic problems and directions of progressive rehabilitation of managing systems of high-tech complex of Russia. Microeconomics, 6, 5-24.

Dmitriev, O. N. (2019). Performance of optimization problem concerning distribution of external high-tech corporation orders between its member enterprises. Microeconomics, 2, 18-32.

Dmitriev, O. N., \& Dergunov, A. I. (2003). Intrafirm management of internal competition between departments and employees. Monograph. Moscow: Gnome and D.

Dmitriev, O. N., \& Dergunov, A. I. (2004). Intrafirm management concerning interdepartment and interpersonal competition within scope of enterprise. Monograph. Moscow: Gnome and D. 
Dmitriev, O. N., \& Novikov, S. V. (2017b). Concept of total economic and financial presentation of the project for creating commercial hi-tech product park in the framework of state order. Herald of Tver State University. Series "Economics and Management", 4, 21-32.

Dmitriev, O. N., \& Novikov, S. V. (2017a). Conception of managing of fuzzy institutional meso-level organizational separations in context of product projects internationalization, European Research Studies Journal, 20(4B), 277-289.

Dmitriev, O. N., \& Novikov, S. V. (2018a). Concept of management interpretation and aprioristic convergence estimation of innovative federal intention programs. Innovations, 4, 63-77.

Dmitriev, O. N., \& Novikov, S. V. (2018b). Transformation of Russian tax system as part of integration of economy into international high-technology production field of socio-economic systems. European Research Studies Journal, 21(4), 400-413.

Dmitriev, O. N., Minaev, E. S., Yekshembiev, S. H., Demchenko, O. F., Pilyugina, N. Y., Lyubaeva, J. I., \& Dubovik, M. V. (2011). Concept of mesolevel program-target management in aviation industry of the Russian Federation. Monograph. Moscow: MAI Publishing.

Dmitriev, O. N., Yekshembiev, S. H., Lyubaeva, J. I., Koval'kov, Ju. A., \& Minaev, E. S. (2013). Strategic corporate governance (fundamental and applied problems. Monograph). Moscow: MAI-PRINT Publishing.

Dubovik, M. V. (2009). Methodological problems of municipal management substantiation of counterparty competitiveness of industrial complex of city of Russia. Moscow: KnoRus.

Fellhauer, A., \& Strożek, A. (2010). Lean intra-corporate supply chain management for complex organizations. In International Heinz Nixdorf Symposium. Springer, Berlin, Heidelberg.

Kanashchenkov, A. I., Dmitriev, O. N., Koval'kov, Ju. A., Dergunov, A. I., \& Minaev, E. S. (2005). Interaction management of enterprise with an integrated system of subcontractors. Moscow: Good Word.

Kirbitova, S. V. (2019). Import substitution: the essence, implementation practice, strategic priorities and features of customs mechanism in Russia. Monograph. Kazan: Book.

Milovanov, P. D. (2014). Organizational and economic mechanism for sub-stantiating decisions on enterprises re-corporatization of rocket and space industry in Russia. Dissertation for the competition degrees of candidate of economic sciences $(P h D)$. Moscow: Moscow Aviation Institute.

Petukhova, M. S. (2016). Institutional and informal employment in the context of the economic crisis: based on materials from the Kaluga Region. Dissertation for the competition degrees of candidate of social sciences $(P h D)$. Moscow: RGTU.

Pilyugina, N. Y. (2008). Target budget programming of industrial complex of municipality of Russia. Monograph. Moscow: KnoRus.

Rodionov, A. M. (2004). Internal corporate fiscal management. Monograph. Moscow: Gnome and D.

Shubin, G. V. (2005). Conflictology of the forthcoming wars (2nd ed.). Moscow: Publishing house of Vorob'ev A.V.

Zuev, A. A. (2014). Organizational and economic mechanism of organizational reengineering of industrial enterprises with branches of multi-country deployment. Dissertation for the competition degrees of candidate of economic sciences $(P h D)$. Moscow: Moscow Aviation Institute.

\section{Copyrights}

Copyright for this article is retained by the author(s), with first publication rights granted to the journal.

This is an open-access article distributed under the terms and conditions of the Creative Commons Attribution license (http://creativecommons.org/licenses/by/4.0/). 